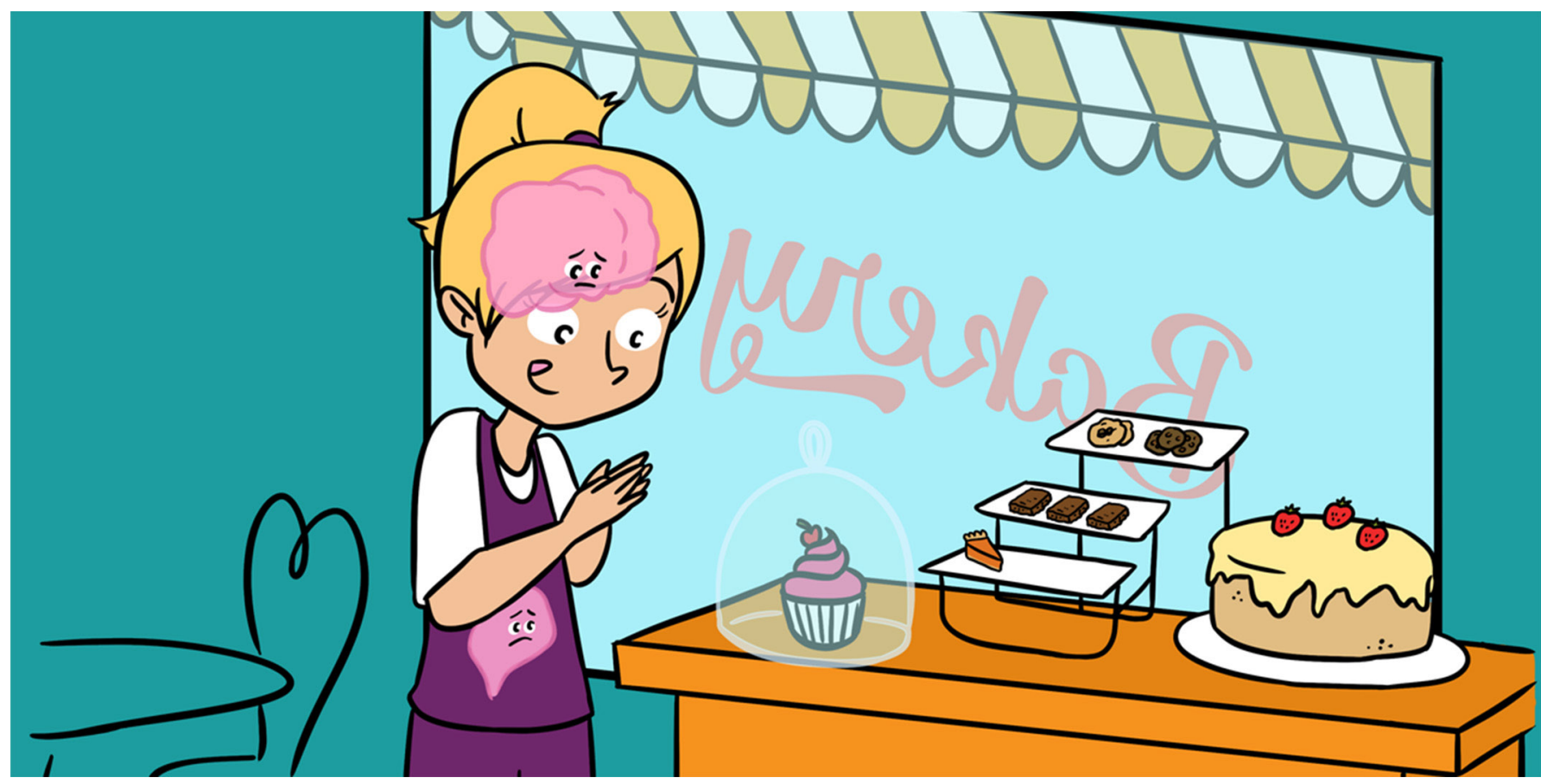

\title{
HAPPY GUT BACTERIA, HAPPY BRAIN: THE MICROBIOTA-GUT=BRAIN AXIS
}

\section{Juan M. Lima-Ojeda ${ }^{1,2 *}$, Rainer Rupprecht ${ }^{1}$ and Thomas C. Baghai ${ }^{1}$}

${ }^{1}$ Department of Psychiatry and Psychotherapy, University of Regensburg, Regensburg, Germany

${ }^{2}$ Neuroscience Center, Helsinki Institute of Life Science, University of Helsinki, Helsinki, Finland

YOUNG REVIEWERS:

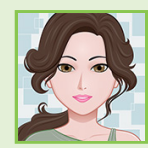

AMELIE

AGE: 10

ARMAN

AGE: 10

(2) ARMIN

AGE: 10
On Earth, we find an amazing number of creatures living together. Each creature is unique. All of them interact together, without borders, making this world-our world-a beautiful place to live. Bacteria are tiny organisms present almost everywhere, including on and in our bodies. Gut bacteria have a strong communication with the brain. A correct communication between gut bacteria and the brain is important for adequate mental health. Situations that damage our gut bacteria are able to harm our brains. Moreover, mental stress can damage bacteria living in the gut. We need to take care of our gut bacteria. A balanced diet, including fish, vegetables, cereals, fruits, and water can help our gut bacteria to be healthy. Healthy gut bacteria will have a positive effect on the brain and our moods. "Happy gut bacteria" will help us to have "happy brains." 


\section{BACTERIA: TINY ORGANISMS LIVING IN AND ON THE BODY}

You have most likely heard about bacteria. Bacteria are very tiny creatures that are difficult to see without a microscope. They live almost everywhere. Bacteria are present in what we eat and touch. They live in and on our body. It is possible to find bacteria living in the gut or on the skin. Many millions of them inhabit our bodies. We have more bacteria than human cells in our bodies.

Normally, we associate bacteria with illness. We say that bacteria are dangerous only if they cause a disease. However, most bacteria in and on our bodies are beneficial for our health. Most of the time the body is able to control the "bad bacteria". When the body fails to control them, it is necessary to visit a doctor. Doctors will evaluate whether we need any treatment to control bacteria or not. There are drugs that can kill bacteria or prevent them from growing. These drugs are called antibiotics. It is important to know that antibiotics kill both bad bacteria and good bacteria. So, it is important to take antibiotics only if it is really necessary, in order to keep the good bacteria alive.

Throughout our lives, we acquire bacteria. Each part of the human body has different types of bacteria. Bacteria living in the mouth are different from those ones living on the hair. Bacteria arrive in our bodies very early. For example, when we are born, we acquire our first bacteria through the contact with the skin of our mothers. Also, when we are newborns, we receive a significant number of bacteria from the food that we receive. Breast milk is one of the main sources of our first good bacteria.

MICROBIOTA

Microorganisms living in a particular environment. For example, the human microbiota is the group of microorganisms living in and on the human body.

\section{GASTROINTESTINAL} TRACT

An organ that includes the mouth, esophagus, stomach, and intestines. This is where digestion of food takes place. It is the home of a large number of bacteria.

\section{GUT MICROBIOTA: A PARADISE FOR BACTERIA IN THE BODY}

The human microbiota is the word we use to refer to the entire population of bacteria and other organisms living in and on the human body. The gastrointestinal tract is the part of the body with the largest population of bacteria living in it: around 100 trillion bacteria live there [1]. The mouth, esophagus, stomach, and intestines form the gastrointestinal tract. Bacteria and other organisms living in the gastrointestinal tract are called the gut microbiota. Throughout this article, we will focus on gastrointestinal bacteria.

Every time that we eat or drink something, it goes into the gastrointestinal tract. This is where digestion of food takes place. Digestion is a process where enzymes and acids convert food into very small fragments that can be absorbed by the gut. Enzymes are molecules that help 
HORMONES

(SINGULAR

HORMONE)

Molecules that allow the endocrine cells to communicate with other cells of the body. They are important to manage the energy that the body needs.

\section{MICROBIOTA-}

GUT-BRAIN (MGB) AXIS

\section{A bidirectional} connection between gut bacteria and the brain. It is a link between the nervous system, the endocrine system, and the immune system.

\section{Figure 1}

The microbiotagut-brain (MGB) axis is a link between gut bacteria and brain. It is a bidirectional axis that uses the vagus nerve as main connection. This figure includes the hypothalamicpituitary-adrenal (HPA) axis and its link with the MGB axis. to convert something into another thing very quickly. For example, in the gastrointestinal tract, enzymes convert pieces of food into tiny bits. Gastrointestinal cells produce these enzymes and acids. Together with gastrointestinal cells, gut bacteria help the body with food digestion. From digestion, the human body obtains nutrients, such as proteins, sugars, fats, and vitamins that the human body requires to work and grow. Bacteria also help to produce some of these nutrients. Bacteria have the capacity to convert food molecules into energy for the human body. In fact, gut bacteria produce around $10 \%$ of the energy that the body uses [2]. In the human body, the endocrine system manages the energy that the body needs. Endocrine cells produce hormones, which are molecules that allow the endocrine cells to communicate with other cells of the body. Through this communication, the endocrine system knows whether a group of cells needs more energy or if it has too much energy.

In humans, the immune system protects the body against illness. The presence of bacteria in and on the human body helps us to have a stronger immune system. The immune system learns from bacteria how to protect the body against illness. When the body has contact with bacteria, it increases its defenses. This helps to reduce bad bacteria and to improve the environment for good bacteria, making the healthy gastrointestinal tract a paradise for the good bacteria.

\section{THE MICROBIOTA-GUT-BRAIN AXIS: A CONNECTION BETWEEN GUT BACTERIA AND THE BRAINS}

The microbiota-gut-brain (MGB) axis is a connection between gut bacteria and the brain (Figure 1). It is like a direct phone line between

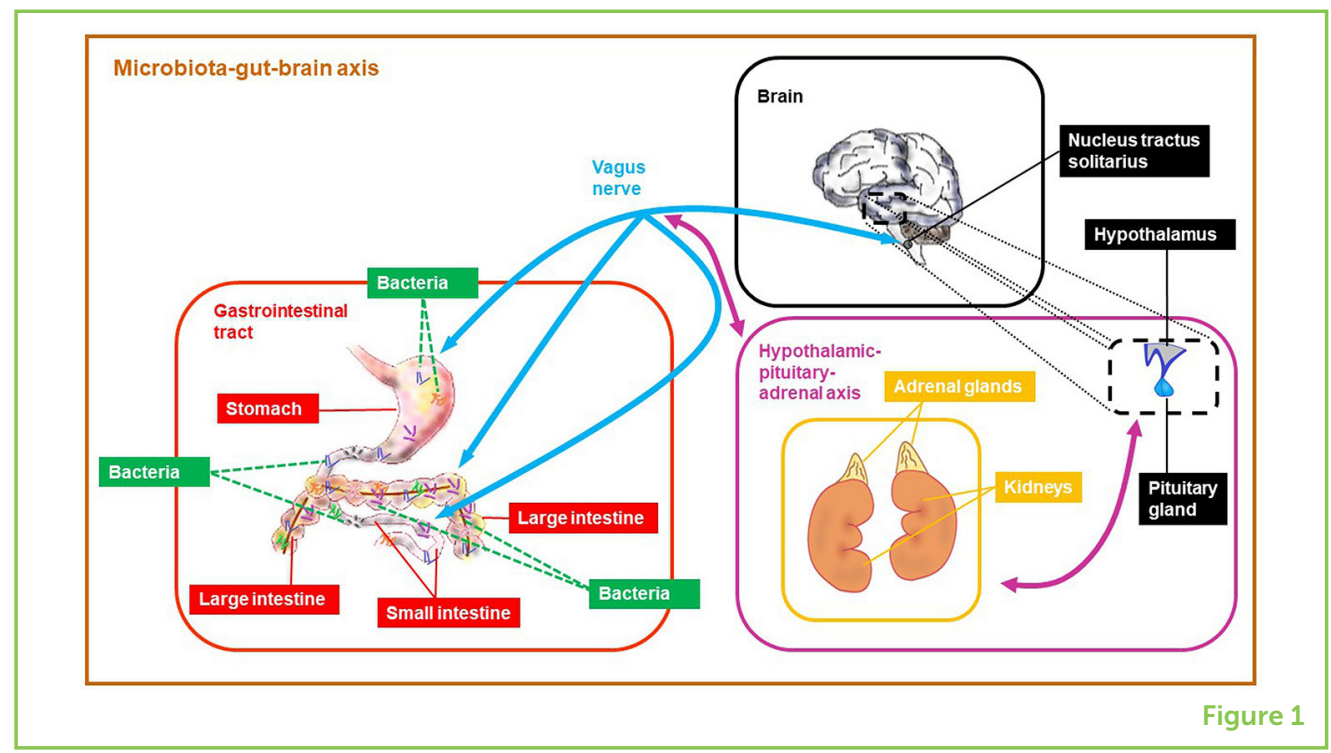




\section{Figure 2}

The microbiotagut-brain (MGB) axis links the nervous system, the endocrine system, and the immune system. The communication between these systems is mainly possible through the vagus nerve.

\section{VAGUS NERVE}

A long nerve that links the heart, gastrointestinal tract, and lungs to the brain.

\section{HYPOTHALAMUS}

A brain region that controls emotions and functions like hunger and thirst.

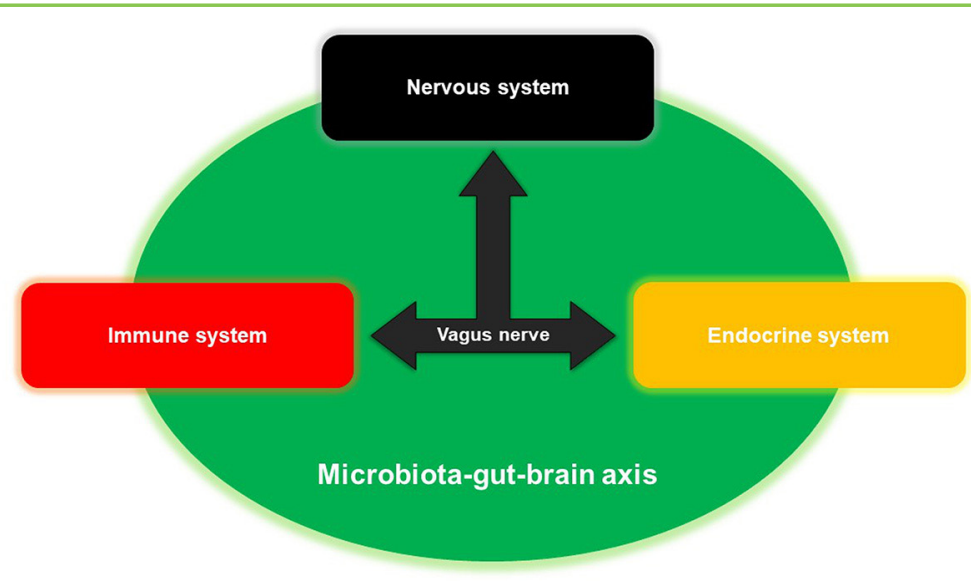

Figure 2

gut bacteria and the brain. The MGB axis is a neuroendocrine-immune system. That means that it links the nervous system, the endocrine system, and the immune system (Figure 2).

The brain is part of the nervous system. It is the main control center of the body. The brain orders our muscles to move. It interprets all the things that we sense. The brain is the origin of our thoughts and mood. Scientists divide the nervous system into two subsystems: the central nervous system, which that includes the brain and spinal cord, and the peripheral nervous system, which includes all the nerve connections outside of the brain and spinal cord.

The gastrointestinal tract is connected to the brain through an important nerve called vagus nerve. The vagus nerve is like a cable that links the heart, gastrointestinal tract and lungs to the brain. The vagus nerve links to an area of the brain called the hypothalamus, which is a brain region that controls hunger and emotions.

The MGB axis uses the vagus nerve as a main phone line. This communication goes in both directions, meaning that the gut microbiota can communicate with the brain through the vagus nerve, but the brain can also communicate with the gut microbiota using the same axis.

\section{GUT MICROBIOTA AND MOOD REGULATION: HAPPY BACTERIA, HAPPY BRAIN}

Since the hypothalamus controls emotions, it is also an important brain structure for stress regulation. Stress is the response of the body to something that happens in our environment. Examples of daily things that induce stress are activities such as practicing sports, going to 
HYPOTHALAMIC-

PITUITARY-ADRENAL

\section{(HPA) AXIS}

A system that includes the hypothalamus, pituitary and adrenal glands. It links the nervous system to the endocrine system. It controls the response of our bodies to stress.

\section{CORTISOL}

A hormone produced by the HPA axis that prepares the body to cope with stressincreasing blood sugar, suppressing the immune system and promoting the mobilization of fats and proteins. school, and sitting for an exam. In the human body, the nervous system and another axis, called the hypothalamic-pituitary-adrenal (HPA) axis, are the main systems that respond to stress. The HPA axis includes glands that produce a substance called cortisol, which is a hormone that prepares the body to cope with stressful situations. This hormone tells the body's cells that they need to produce enough energy to deal with the stressful situation. Some environmental situations that worry us or make us sad can cause a stress response in the body that lasts for weeks, months, or even years. This long-term stress can alter the normal function of the HPA axis. That means that after a long-term worrisome situation, the human body can have problems regulating its response to stress. At the level of the MGB axis, long-term stress can damage the bacteria living in the gut. This happens because the HPA axis is also linked to the MGB axis. Since communication through the axis can happen in either direction, stress factors that affect the brain can also harm the gut and the bacteria living in it. A difficult life situation can be enough to reduce the diversity (number of different kinds) of gut bacteria and to increase the numbers of bad bacteria in the gut. These changes in the gut microbiota can cause changes in the brain, as well-increasing the risk of brain disorders such as depression. Depression is a brain disorder that affects one's feelings. People with depression feel sad and guilty for a long time. However, we do not know the exact mechanism that produces depression. It is possible that the changes in the body that result in depression involve the participation of the three systems that make up the MGB axis: the nervous, endocrine, and immune systems. Together with emotional stress, malnutrition, and high use of antibiotics are risk factors that may alter the MGB axis and that increase the risk of developing depression.

\section{TAKING CARE OF THE GUT MICROBIOTA: WATCH WHAT YOU EAT}

A correct communication between the gut bacteria and the brain is important in order to have adequate mental health. The MGB axis makes this communication possible. Scientists are still trying to understand exactly how this axis works. However, it is clear that there is an association between a healthy brain and a functional MGB axis.

Diet is probably the most important strategy for maintaining a healthy MGB axis. A balanced diet, including fish, vegetables, cereals, fruits, and water is important to keep both a functional MGB axis and a good mood. The food that we consume has a direct impact on our bacteria and their home-our bodies. 
Patients suffering from depression may benefit from this research on the MGB axis. These patients might be able to improve their condition by eating a healthy diet. Our habits, such as diet, definitely influence our moods, so we should take care with our diets. Eat well and be happy!

\section{AUTHOR CONTRIBUTIONS}

JL-O, RR and TB are equally contributing authors of the original source article. JL-O wrote the first draft of this manuscript. All authors contributed to manuscript revision, read and approved the submitted version.

\section{FUNDING}

$\mathrm{JL}-\mathrm{O}$ is supported by a Feodor Lynen Research Fellowship from the Alexander von Humboldt Foundation. The original source article was supported by the German Federal Ministry of Education and Research (Bundesministerium für Bildung und Forschung, BMBF), Research Grant No. 01EE1401B to RR and TB.

\section{ORIGINAL SOURCE ARTICLE}

Lima-Ojeda, J. M., Rupprecht, R., and Baghai, T. C. 2017. "I am I and my bacterial circumstances": linking gut microbiome, neurodevelopment, and depression. Front. Psychiatry 8:153. doi: 10.3389/fpsyt.2017.00153

\section{REFERENCES}

1. Pacheco, A. R., and Sperandio, V. 2015. Enteric pathogens exploit the microbiota-generated nutritional environment of the gut. Microbiol. Spectr. 3. doi: 10.1128/microbiolspec.MBP-0001-2014

2. Elson, C. O., and Alexander, K. L. 2015. Host-microbiota interactions in the intestine. Dig. Dis. 33:131-6. doi: 10.1159/000369534

SUBMITTED: 28 August 2018; ACCEPTED: 21 January 2019; PUBLISHED ONLINE: 11 February 2019.

EDITED BY: Viduranga Y. Waisundara, Australian College of Business and TechnologyKandy Campus, Sri Lanka

CITATION: Lima-Ojeda JM, Rupprecht R and Baghai TC (2019) Happy Gut Bacteria, Happy Brain: The Microbiota-Gut-Brain Axis. Front. Young Minds 7:15. doi: 10.3389/ frym.2019.00015 

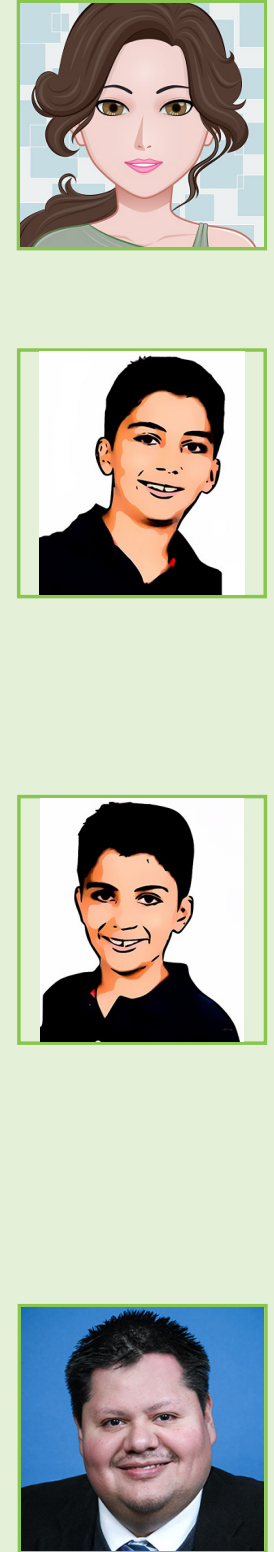

CONFLICT OF INTEREST STATEMENT: The authors declare that the research was conducted in the absence of any commercial or financial relationships that could be construed as a potential conflict of interest.

COPYRIGHT (c) 2019 Lima-Ojeda, Rupprecht and Baghai. This is an open-access article distributed under the terms of the Creative Commons Attribution License (CC BY). The use, distribution or reproduction in other forums is permitted, provided the original author(s) and the copyright owner(s) are credited and that the original publication in this journal is cited, in accordance with accepted academic practice. No use, distribution or reproduction is permitted which does not comply with these terms.

\section{YOUNG REVIEWERS}

\section{AMELIE, AGE: 10}

I am fascinated about Science, in particular about the human body and how it works. Recently I have illustrated a science book for children. I also love traveling and my favorite trips were hiking on the Rila Mountains in Bulgaria and feeding and washing elderly elephants at a rehabilitation center for elephants in Thailand.

\section{ARMAN, AGE: 10}

$\mathrm{Hi}$, my name is Arman and I live in Canada. I am 10 years old and I am in fifth grade. I can speak three languages fluently, English, French, and Persian. I enjoy playing Guitar, Basketball, and LEGO. I like to read The Hobbit by J. R. R Tolkien, Harry Potter and The Cursed Child by J. K. Rowling, and Lord of the Rings by J. R. R Tolkien. My mom is a Scientist and I love Science, especially Biology. I like reading and learning about how the cells of our body work in health and disease.

\section{ARMIN, AGE: 10}

Hello, my name is Armin and I am 10 years old. I live in Canada and I am in fifth grade. In my free time, I like to play the piano, read books, and play sports. I can talk three languages, English, French, and Persian. I thought it would be really cool to be a reviewer and be involved in a scientific publication. I am interested in reviewing articles for Frontiers for Young Minds because I want to learn about how our brain works; how our cells communicate with each other and how we get sick.

\section{AUTHORS}

\section{JUAN M. LIMA-OJEDA}

I am a Physician and Scientist working at the University of Helsinki. My area of work is Psychiatry. I am trying to understand both the causes and mechanisms that produce mental illnesses such as depression, anxiety, and schizophrenia, with the objective to improve the treatment options for patients. I like to experience different cultures and to enjoy the diversity of this world. Moreover, I love to spend time with my family. *juan.limaojeda@helsinki.fi 

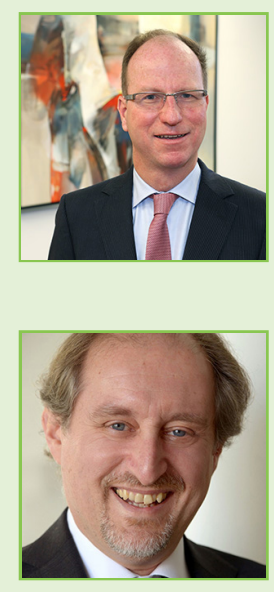

\section{RAINER RUPPRECHT}

I am Chair of Psychiatry and Psychotherapy at the University of Regensburg, Germany. I am interested in new treatments for patients suffering from depression and anxiety. I am also a musician and like to play chamber music.

\section{THOMAS C. BAGHAI}

I am Director of Medical Services of the Medical Institutions of the District of Upper Palatinate (Oberpfalz) in Bavaria, Germany. I am also Principal Investigator of the Research Group of Clinical Neurosciences and Depression Research at the University of Regensburg. My main research interest is to optimize the treatment of patients suffering from mental illnesses such as depression and anxiety. In addition, I am interested in the multiple interactions between depression and heart disease. When I am not working, I like to experience traveling, hiking, climbing, mountain biking, and horseback riding. 